\title{
The promise of omega-3 against sudden unexpected death in epilepsy: until further notice, it remains innocent, until proven guilty
}

\author{
Promessa do ômega-3 contra a morte súbita em epilepsia: até segunda ordem, continua
} inocente, até que se prove o contrário

Fulvio Alexandre Scorzaํ. Antonio Carlos Lopes², Roberta Monterazzo Cysneiros ${ }^{3}$, Ricardo Mario Arida4, Mauricio Rocha e Silva ${ }^{5}$

\begin{abstract}
The present paper highlighted the importance of the recommended levels of fish consumption or omega-3 supplementation in order to minimize the frequency of seizures in people with uncontrolled epilepsy and, especially, to reduce the occurrence of sudden unexpected death in epilepsy (SUDEP).
\end{abstract}

Key words: omega-3, SUDEP, seizures, epilepsy.

\section{RESUMO}

O presente trabalho destacou a importância dos níveis recomendados de consumo de peixe ou suplementação de ômega-3 com o intuito de minimizar a frequência de crises epilépticas em pessoas com epilepsia refratária e, especialmente, de reduzir a ocorrência de morte súbita inesperada em epilepsia (SUDEP).

Palavras-Chave: ômega-3, SUDEP, convulsões, epilepsia.

Epilepsy is a common and very heterogeneous chronic neurological condition ${ }^{1,2}$. Often, it is still seen as a benign condition in which individuals only have seizures. Unfortunately, the story is not as simple as it seems. Observational data over the years have shown that epilepsy is a malignant condition that has a high rate of premature death compared with the general population ${ }^{3-5}$. Thus, sudden unexpected death in epilepsy (SUDEP) is the most important fatal complication of epilepsy ${ }^{6}$. In fact, it is responsible for 7.5 to $17 \%$ of all deaths in people with epilepsy and has an incidence among adults between 1:500 and 1:1,000 patient-years?

Recent research suggests that multiple risk factors may contribute for SUDEP, such as refractoriness of the epileptic condition, increased frequency of convulsive seizure, antiepileptic medication (polytherapy with antiepileptic drugs), longer duration of epilepsy, young age at onset, male sex, symptomatic cause, and lamotrigine therapy (in people with idiopathic generalized epilepsy) $)^{5,68-10}$. The cause or causes of SUDEP is/are still unknown, however experimental and clinical research suggest that the main mechanism involved is autonomic dysregulation, i.e., respiratory and cardiovascular abnormalities during and after seizures ${ }^{6,9-11}$.

In this context, relevant putative mechanisms involved are cardiac arrhythmia, due to myocardial ischemia; electrolyte disturbances; arrhythmogenic drugs; or transmission of the epileptic activity via the autonomic nervous system to

'Disciplina de Neurologia Experimental, Escola Paulista de Medicina, Universidade Federal de São Paulo (Unifesp), São Paulo SP, Brazil;

²Departamento de Medicina, Escola Paulista de Medicina, Unifesp, São Paulo SP, Brazil;

${ }^{3}$ Programa de Pós-graduação em Distúrbios do Desenvolvimento da Universidade Presbiteriana Mackenzie, São Paulo SP, Brazil;

${ }^{4}$ Departamento de Fisiologia, Escola Paulista de Medicina, Unifesp, São Paulo SP, Brazil;

${ }^{5}$ Hospital das Clínicas da Faculdade de Medicina da Universidade de São Paulo (USP), São Paulo SP, Brazil.

Correspondence: Fulvio Alexandre Scorza; Disciplina de Neurologia Experimental; Rua Botucatu 862 / Edifício Leal Prado; $04023-900$ São Paulo SP - Brasil; E-mail: scorza.nexp@epm.br

Support: Fundação de Amparo à Pesquisa do Estado de São Paulo (FAPESP), Cooperação Interinstitucional de Apoio à Pesquisa sobre o Cérebro (CInAPCeFAPESP), Conselho Nacional de Desenvolvimento Científico e Tecnológico (CNPq) and Institutos Nacionais de Ciência e Tecnologia/ Ministério da Ciência e Tecnologia (INCT/MCT).

Conflict of interest: There is no conflict of interest to declare.

Received 11 June 2012; Received in final form 13 July 2012; Accepted 20 July 2012 
the heart ${ }^{9,11-13}$. Actually, it is clear that SUDEP is mainly (but not exclusively) a problem for people with chronic uncontrolled epilepsy ${ }^{10}$, but our understanding of the best way to prevent is still incomplete. As SUDEP is probably a seizurerelated event, the successful seizure control is the best preventive measure ${ }^{1,9}$. Furthermore, others strategies have been suggested, which could be useful in reducing its risk ${ }^{10,14,15}$, although strict evidence for their effectiveness is still lacking. Following this line of reasoning, the ultimate goal of research in SUDEP is to develop new methods for its prevention and actions other than medical and surgical therapies that could be very useful. Nutritional aspects, i.e., omega-3 fatty acids (omega-3 FAs), could have a prominent place in this scenario, since promising research and evolving clinical experience support the idea that the omega-3 FAs have anti-seizure properties, as well as a possible effect in the prevention of cardiovascular abnormalities and a reduction of SUDEP occurrence $^{14-16}$. Thus, a number of considerations could be put forward to explain these findings.

Firstly, we must bear in mind that polyunsaturated FAs are present at high levels in the brain ${ }^{17}$. The four polyunsaturated FAs are designated eicosapentaenoic acid (EPA) and docosahexaenoic acid (DHA), which are omega-3 FAs; and dihomogammalinolenic (DGLA) and arachidonic acids (AA), which are n-6 FAs (omega-6), comprising over $10 \%$ (w/w) of the brain dry weight ${ }^{17,18}$. Fish and fish oil long-chain omega-3 FAs may interfere with certain nervous system diseases ${ }^{19}$. Furthermore, a diet rich in fish may be a good way to improve the development of the brain and, undeniably, omega-3 FAs are important for the treatment and prevention of cardiovascular and neurological diseases, including epilepsy ${ }^{16,19}$.

Concerning epilepsy, Spirer et al. suggested, in 1994, that omega-3 FAs may be used as a prophylactic to prevent febrile seizures in susceptible children ${ }^{20}$. The authors postulated that since the most important substance mediating the febrile response is interleukin-1 (IL-l), febrile convulsions could be prevented by reducing the concentration of secreted IL-l and supplementing the diet with omega-3 FAs ${ }^{20}$. In the same year, Yehuda et al. demonstrated anticonvulsant properties in a mixture of non-esterified alpha-linolenic and linoleic acids with a ratio of 1:4 (SR-3) in four rat models of epileptic seizure $^{21}$. In brief, these authors found that treatment with SR-3 (about $40 \mathrm{mg} / \mathrm{kg}$ intra-peritoneal) in a three-week prior to challenge was effective in each experimental model and caused up to a 22-fold increase in latency to major motor seizures, up to $84 \%$ reduction in the number of rats with seizures, and up to $97 \%$ reduction in the duration of seizures ${ }^{21}$.

Four years later, using the cortical stimulation seizure model in rats, Voskuyil et al. ${ }^{22}$ demonstrated a long-term modest anticonvulsant effect as a result of the administration of omega-3 FAs. Moreover, pharmacology studies show that omega-3 FAs applied extra-cellularly raise the stimulatory thresholds of CA1 neurons in hippocampal slices ${ }^{23}$. In a clinical study, it was reported on an open trial in which five patients took omega-3 FAs supplements ${ }^{24}$. In that study, a special spread, containing $65 \%$ omega- 3 FAs, was added to the daily diet of five patients with epilepsy ${ }^{24}$. The patients consumed $5 \mathrm{~g}$ of this spread at every breakfast for 6 months, and all of them showed a marked reduction in both frequency and strength of epileptic seizures, suggesting that a dietary supplement containing omega-3 FAs may be beneficial for the suppression of some cases of epileptic seizures ${ }^{24}$.

In the first randomized, placebo-controlled parallel trial of omega-3 FAs supplementation in 57 patients with refractory epilepsy, seizure frequency was reduced over the first 6 weeks of treatment in the supplemented group, however this effect was not sustained over the 12 -week total trial ${ }^{25}$. The authors believe that the loss of effect following the initial six weeks is a result of omega-3 FAs preparations, doses, treatment duration, and sample sizes ${ }^{25}$. Specifically, the researchers used in their study a total daily dose of approximately $1.7 \mathrm{~g}$ omega-3 FAs (approximately $1 \mathrm{~g}$ EPA and $0.7 \mathrm{~g}$ DHA), but believe that higher doses and different omega-3 FAs ratios should be tested ${ }^{25}$.

Recently, our research was the first to demonstrate that a chronic treatment with omega-3 FAs promoted neuroprotection and positive plastic changes in the hippocampal formation of rats with epilepsy ${ }^{26,27}$. In addition, Taha et al. assessed the dose-dependent anticonvulsant effects of a fatty acid mixture with linoleic and alpha-linolenic acids in a 4:1 ratio (the SR-3 compound), and demonstrated that linoleic and alpha-linolenic polyunsaturated FAs in a 4:1 ratio raises omega-3 FAs composition of unesterified FAs in the brain and increases resistance to pentylenetetrazol-induced seizures ${ }^{28}$. In 2009, we have described the effectiveness of daily intake of a moderate amount of omega-3 FAs in a case of canine epilepsy $^{29}$. Briefly, a two-year-old female Great Dane with history of idiopathic epilepsy initiated the pharmacological treatment under the supervision of a veterinary neurologist aimed at seizure control ${ }^{29}$.

A trial therapy with phenobarbital $(2.5 \mathrm{mg} / \mathrm{kg}$, twice a day orally) failed to adequately control the seizures: after eight weeks of treatment, there remained two seizure episodes per month $^{29}$. Typically, potassium bromide is used to supplement phenobarbital in refractory cases. However, in this case, it was decided to supplement the dog's diet with moderate amounts of omega-3 FAs (oral, $2 \mathrm{~g}$ /day). The frequency of the epileptic seizures markedly decreased after 50 days of combination therapy with phenobarbital and omega-3 FAs. During the subsequent 18-month period, seizure frequency fell to one per three months, a reduction of about $85 \%^{29}$. In 2012, Yuen et al. evaluated a non-randomized open assessment of EPA supplementation, omega-3 FAs, in ten people with refractory focal seizures ${ }^{30}$. The authors showed that six people had fewer seizures during the supplementation period compared with baseline, and one other person had markedly 
reduced seizure severity, suggesting that although the small number of participants and open nature of the study, interpretation of the results is difficult, but a possible weak effect of EPA on seizures cannot be discounted ${ }^{30}$.

From these results, we are totally in agreement with the proposal of Taha et al., therefore future clinical trials involving the omega-3 FAs should involve higher doses and longer periods of administration in order to definitively assess their possible anti-seizure effects ${ }^{16}$. We also must consider that the data presented so far confirm that omega-3 FAs reduce the frequency of epileptic seizures, promote neuroprotection and establish the safety of omega-3 FAs supplementation in people and animal models of refractory epilepsy $y^{14,15,26,27,29,31}$.

Concerning SUDEP, there is now great interest in omega-3 FAs supplementation for its prevention. As we know, the association between fish consumption and low rates of cardiovascular disease was studied nearly 40 years ago in the seafood diets consumed by Greenland Eskimos, Alaskan Natives, and Japanese people residing in fishing villages ${ }^{32}$. Actually, several studies have shown that omega-3 FAs have protective effects in preventing coronary heart disease, reducing arrhythmias and thrombosis, lowering plasma triglyceride levels, and reducing blood clotting tendency ${ }^{33}$. Furthermore, substantial evidence from epidemiological and case-control studies indicate that omega-3 FAs reduce the risk of cardiovascular mortality, with a potent effect on sudden cardiac death ${ }^{34,35}$. Thus, considering that omega-3 FAs per se are able to minimize cardiac arrhythmias and sudden cardiac deaths ${ }^{34,35}$, Yuen and Sander ${ }^{36}$ proposed the interesting hypothesis that omega-3 FAs supplementation in people with refractory epilepsy may not only reduce seizures but also cardiac arrhythmias and hence SUDEP. Four years later, our research group reinforced this hypothesis ${ }^{37}$ from two experiments conducted in our laboratory. Firstly, we evaluated the heart rate, in vivo (ECG) and isolated ex vivo preparation (Langendorf preparation) of rats with epilepsy ${ }^{38}$. Our results showed significant differences in the mean heart rate in vivo between the groups. In contrast, we did not find differences in the isolated ex vivo situation, suggesting a central nervous system modulation of the heart, which could explain SUDEP. Secondly, Scorza et al. (unpublished data) performed a similar set of experiments (heart rate in vivo and isolated ex vivo preparation) of rats with epilepsy before and after chronic omega-3 FAs supplementation. Their results showed differences in the mean heart rate in vivo, but surprisingly, none in heart rate could be observed in the isolated ex vivo condition.

On the whole, omega-3 FAs consumption improves vascular and cardiac hemodynamics, triglycerides, autonomic control, inflammation, thrombosis, and arrhythmia and reduces risk of cardiac death ${ }^{35}$. In this context, Brazilian and international guidelines have converged on consistent recommendations for the general population to consume at least $250 \mathrm{mg} /$ day of long-chain omega-3 FAs or at least two servings/week of oily fish ${ }^{35}$.

Finally, it is very important to emphasize that supplementation with omega-3 FAs for individuals with epilepsy is not a substitute for anticonvulsant medications. Thus, neurologists should recommend fish consumption for their patients, and government and public health agencies should implement strategies to improve attainment of the recommended levels of fish consumption or omega-3 FAs supplementation in order to minimize the frequency of seizures in people with uncontrolled epilepsy and mainly to reduce the occurrence of SUDEP in these individuals.

\section{References}

1. Sander JW. The epidemiology of epilepsy revisited. Curr Opin Neurol 2003;16:165-710.

2. de Boer HM, Mula M, Sander JW. The global burden and stigma of epilepsy. Epilepsy Behav 2008;12:540-546.

3. Nashef L, Ryvlin P. Sudden unexpected death in epilepsy (SUDEP): update and reflections. Neurol Clin 2009;27:1063-1074.

4. Duncan JS, Sander JW, Sisodiya SM, Walker MC. Adult epilepsy. Lancet 2006;367:1087-1100.

5. Nei M, Hays R. Sudden unexpected death in epilepsy. Curr Neurol Neurosci Rep 2010;10:319-326.

6. Surges R, Sander JW. Sudden unexpected death in epilepsy: mechanisms, prevalence, and prevention. Curr Opin Neurol 2012;25:201-207.

7. Schuele SU, Widdess-Walsh P, Bermeo A, Lüders HO. Sudden unexplained death in epilepsy: the role of the heart. Cleve Clin J Med 2007;74(Suppl):S121-S127.

8. Hesdorffer DC, Tomson T, Benn E, et al. ILAE Commission on Epidemiology; Subcommission on Mortality. Combined analysis of risk factors for SUDEP. Epilepsia 2011;52:1150-1159.

9. Surges R, Thijs RD, Tan HL, Sander JW. Sudden unexpected death in epilepsy: risk factors and potential pathomechanisms. Nat Rev Neurol 2009;5:492-504.
10. Tomson T, Nashef L, Ryvlin P. Sudden unexpected death in epilepsy: current knowledge and future directions. Lancet Neurol 2008;7: 1021-1031.

11. Stollberger C, Finsterer J. Cardiorespiratory findings in sudden unexplained/unexpected death in epilepsy (SUDEP). Epilepsy Res 2004;59:51-60.

12. Surges R, Taggart P, Sander JW, Walker MC. Too long or too short? New insights into abnormal cardiac repolarization in people with chronic epilepsy and its potential role in sudden unexpected death. Epilepsia 2010;51:738-744.

13. Nei M, Ho RT, Abou-Khalil BW, et al. EEG and ECG in sudden unexplained death in epilepsy. Epilepsia 2004;45:338-345.

14. Scorza FA, Colugnati DB, Pansani AP, Sonoda EY, Arida RM, Cavalheiro EA. Preventing tomorrow's sudden cardiac death in epilepsy today: what should physicians know about this? Clinics 2008;63:389-394.

15. Scorza FA, Arida RM, Terra VC, Cavalheiro EA. What can be done to reduce the risk of SUDEP? Epilepsy Behav 2010;18:137-138.

16. Taha AY, Burnham WM, Auvin S. Polyunsaturated fatty acids and epilepsy. Epilepsia 2010;51:1348-1358.

17. Ohara K. The $n-3$ polyunsaturated fatty acid/dopamine hypothesis of schizophrenia. Prog Neuropsychopharmacol Biol Psychiatry 2007;31:469-474. 
18. Calon F, Cole G. Neuroprotective action of omega-3 polyunsaturated fatty acids against neurodegenerative diseases: evidence from animal studies. Prostaglandins Leukot Essent Fatty Acids 2007;77:287-293.

19. Bourre JM. Roles of unsaturated fatty acids (especially omega-3 fatty acids) in the brain at various ages and during ageing. $J$ Nutr Health Aging 2004;8:163-174.

20. Spirer Z, Koren L, Finkelstein A, Jurgenson U. Prevention of febrile seizures by dietary supplementation with N-3 polyunsaturated fatty acids. Med Hypotheses 1994;43:43-45.

21. Yehuda S, Carasso RL, Mostofsky DI. Essential fatty acid preparation (SR-3) raises the seizure threshold in rats. Eur $J$ Pharmacol 1994:254:193-198.

22. Voskuyl RA, Vreugdenhil M, Kang JX, Leaf A. Anticonvulsant effect of polyunsaturated fatty acids in rats, using the cortical stimulation model. Eur J Pharmacol 1998;341:145-152.

23. Xiao Y, Li X. Polyunsaturated fatty acids modify mouse hippocampal neuronal excitability during excitotoxic or convulsant stimulation. Brain Res 1999;846:112-121.

24. Schlanger S, Shinitzky M, Yam D. Diet enriched with omega-3 fatty acids alleviates convulsion symptoms in epilepsy patients. Epilepsia 2002;43:103-104.

25. Yuen AW, Sander JW, Fluegel D, et al. Omega-3 fatty acid supplementation in patients with chronic epilepsy: a randomized trial. Epilepsy Behav 2005;7:253-258.

26. Ferrari D, Cysneiros RM, Scorza CA, et al. Neuroprotective activity of omega-3 fatty acids against epilepsy-induced hippocampal damage: quantification with immunohistochemical for calcium-binding proteins. Epilepsy Behav 2008;13:36.

27. Cysneiros RM, Ferrari D, Arida RM, et al. Qualitative analysis of hippocampal plastic changes in rats with epilepsy supplemented with oral omega-3 fatty acids. Epilepsy Behav 2010;17:33-38.

28. Taha AY, Filo E, Ma DW, Mclntyre Burnham W. Dose-dependent anticonvulsant effects of linoleic and alpha-linolenic polyunsaturated fatty acids on pentylenetetrazol induced seizures in rats. Epilepsia 2009;50:72-82.

29. Scorza FA, Cavalheiro EA, Arida RM, et al. Positive impact of omega-3 fatty acid supplementation in a dog with drug-resistant epilepsy: a case study. Epilepsy Behav 2009;15:527-528.

30. Yuen AW, Flugel D, Poepel A, Bell GS, Peacock JL, Sander JW. Nonrandomized open trial of eicosapentaenoic acid (EPA), an omega-3 fatty acid, in ten people with chronic epilepsy. Epilepsy Behav 2012;23:370-372.

31. DeGiorgio CM, Miller P. n-3 fatty acids (eicosapentanoic and docosahexanoic acids) in epilepsy and for the prevention of sudden unexpected death in epilepsy. Epilepsy Behav 2008;13:712-713.

32. He K. Fish, long-chain omega-3 polyunsaturated fatty acids and prevention of cardiovascular disease eat fish or take fish oil supplement? Prog Cardiovasc Dis 2009;52:95-114.

33. Smith KM, Sahyoun NR. Fish consumption: recommendations versus advisories, can they be reconciled? Nutr Rev 2005;63: 39-46.

34. Calder PC. n-3 Fatty acids and cardiovascular disease: evidence explained and mechanisms explored. Clin Sci 2004;107:1-11.

35. Mozaffarian D, Wu JH. Omega-3 fatty acids and cardiovascular disease: effects on risk factors, molecular pathways, and clinical events. J Am Coll Cardiol 2011;58:2047-2067.

36. Yuen AW, Sander JW. Is omega-3 fatty acid deficiency a factor contributing to refractory seizures and SUDEP? A hypothesis. Seizure 2004;13:104-107.

37. Scorza FA, Cysneiros RM, Arida RM, Terra-Bustamante VC, Albuquerque M, Cavalheiro EA. The other side of the coin: beneficiary effect of omega-3 fatty acids in sudden unexpected death in epilepsy. Epilepsy Behav 2008;13:279-283.

38. Colugnati DB, Gomes PA, Arida RM, et al. Analysis of cardiac parameters in animals with epilepsy: possible cause of sudden death? Arq Neuropsiquiatr 2005;63:1035-1041. 